\title{
Contribution of Environmental Risk Factors Including Lifestyle to Inequalities Noncommunicable (Chronic) Diseases such as Diabetes
}

\author{
Grochowska-Niedworok E. ${ }^{1}$, Brukało K. ${ }^{2}$, Kardas M. ${ }^{1}$, Całyniuk B. ${ }^{1}$
}

\begin{abstract}
Health inequalities: differences in health status or in the distribution of health determinants between different population groups. Some health inequalities are attributable to biological variations or free choice and others are attributable to the external environment and conditions mainly outside the control of the individuals concerned. 347 million people worldwide have diabetes. In 2012 an estimated 1.5 million deaths were directly caused by diabetes. More than $80 \%$ of diabetes deaths occur in low- and middle-income countries. WHO projects that diabetes will be the 7 th leading cause of death in 2030. Healthy diet, regular physical activity and maintaining a normal body weight can prevent or delay the onset of type 2 diabetes. Risk factors: 1 . Age- the prevalence of diabetes rises steeply with age: ${ }^{*}$ one in twenty people over the age of 65 have diabetes, ${ }^{*}$ and this rises to one in five people over the age of 85 years. The diagnosis of diabetes may be delayed in older people, with symptoms of diabetes being wrongly attributed to ageing. 2. Ethnic: type 2 diabetes is up to six times more common in people of South Asian descent and up to three times more common in those of African and African-Caribbean descent then in the white population. It is also more common in people of Chinese descent and other non-Caucasian groups. 3. Gender: the frequency of diabetes usually is higher in men than in women. This may be because gender compounds other aspects of inequality- women often bear the brunt of poverty, and socio-economic differences in the prevalence of diabetes are more marked for women, probably because of differences in smoking rates, food choices and the prevalence of obesity. 4. Overweight/Obesity: every $1 \mathrm{~kg} / \mathrm{m} 2$ more causes increase risk: cardiovascular diseases $2 \%$, coronary artery disease- $3 \%$, myocardial infarction$5 \%$, heart failure- $5 \%$, peripheral vascular disease- $5 \%$. Health inqualities important in diabetes -modifiable: social-economics (wellbeing, nutrition, education, physical activity, environmental...), health service (access to services for prevention and treatment diabetes) .
\end{abstract}

Keyword: Inequalities, diabetes, risk factors

\section{Introduction}

One of the most important diabetological problems, being at the same time one of the most difficult problems in the whole medicine of the early $21^{\text {st }}$ century, is the increasing prevalence of type 2 diabetes. In the developed countries, it affects a few percent of the population, and this percentage is still growing fast (King et al., 1999). Type 2 diabetes is the cause of premature death, first of all caused by cardiovascular problems, and complications leading to blindness, amputation of limbs and kidney failure (Selby, 1997). The disease has serious psychological and economic consequences, which affect patients, their families, local communities, healthcare system, and so - the whole society.

The World Health Organization estimates that in 1985 there were 30 million people suffering from diabetes in the world, 10 years later $135 \mathrm{~m}$, and in the year $2000-171 \mathrm{~m}$. It is expected that in 2030 there will be about $366 \mathrm{~m}$ people suffering from diabetes. Each year, about $3.2 \mathrm{~m}$ 
people in the world die as a result of complications caused by diabetes. Diabetes has become one of the main metabolic diseases. This means that there is full justification for speaking of an epidemic or even pandemic of this disease. The main causes for the incidence of diabetes include: aging of the society, wrong diet, excessive body weight or obesity, and sedentary lifestyle. However, professional literature stresses especially that the growing number of people with type 2 diabetes is connected with the growing incidence of obesity and aging of the population. What is more, the above factors are modifiable ones (except for age), and are strictly correlated with occurrence of health inequalities.

\section{Health Inequalities}

The popularization of healthcare access starting from the 1950s brought about a clear improvement in the health status of the developed countries societies. However - contrary to the expectations - this tendency has not been accompanied by gradual disappearance of the problem of health status inequalities (Włodarczyk, 2006). This was because the process of health status improvement has not progressed in a uniform way across the whole population. The health status of privileged social groups has been improving faster and in a lasting way, while the inequalities between groups distinguished, for example, based on the income level or education, have been increasing all the time (Sowa, 2007).

When analysing the topical literature, we note problems with a precise definition of the notion of health inequalities. This is because not all differences in the health status of individuals are perceived as inequalities in the meaning used here. There is a natural differentiation between individuals, and the health dimension is one of the expressions of this differentiation. However, the state when all individuals are characterized by equal health status, or live until the same age, is not an achievable goal (Whitehead, 1990). Hence health inequalities - in the considered sense- are socially determined, and biological differences, whether inborn or sex-related, are treated as not connected with the category of inequalities, due to the absence of a direct impact of the individual on their emergence (Włodarczyk, 2006). Taking into consideration such a view of differences in the health status, health inequalities are recognized as systematic and avoidable differences in health results among social groups, so that the less affluent and/or persons finding themselves in other disadvantageous social situations are more prone to diseases and live shorter than persons with higher financial status (Judge et al., 2006). We should also add that the characteristics of the notion of health inequalities is extended to include their being both unwanted and not attributable to the persons afflicted by them (Włodarczyk, 2006).

Here it is also advisable to distinguish between two rather closely related terms: equality in health and equality in access to healthcare (Kaczmarek et al., 2007). In case of equality in health, the goal is effective limitation of permanent differences in the health status between different socioeconomic groups, while in case of equality in healthcare access the goal will be to guarantee healthcare benefits to persons with the same health status, regardless of their socio-economic situation. Hence devoting attention solely to equality in healthcare access does not prevent emergence of health inequalities, though ensuring equality in healthcare is one of the necessary conditions for effective limitation of health inequalities.

Among the health inequalities, of particular importance will be the social ones, since the differentiation in social positions has been proven to bring about structural differentiation in the health status. There is a huge body of empirical evidence confirming the relationship between the social position and the health status and the factors threatening health. We know today that low socio-economic status, which the main component of the social position, is significantly correlated with disease prevalence and early death incidence (Kaplan, 1993). It is estimated that persons occupying low positions in the social structure exhibit at least twice higher risk of 
developing a serious disease and dying prematurely (Wilkinson, 1998). Moreover, a low socioeconomic status facilitates the occurrence of disease risk factors (Kaplan, 1993). Its influence on health is explained, among others, by anti-health lifestyles (Lynch et al., 1997), higher exposure to stress (Wamala et al., 2000), low social support level (Droomers et al., 2000), lower health knowledge level (Anderson, Leppert, 2001), as well as limited access to health services, especially specialist ones (Pell et al., 2000). We can accept the thesis that all things that are more expensive and scarcer become less available for persons with low socio-economic status. The notion of „social inequalities" is inherently connected with that of „social determinants”. The latter notion was introduced to the language and theory of public health in the 1970s, in order to stress the importance of social conditions for health development and protection, which issue used to be underappreciated by the representatives of that area (Graham, 2006). Depending on who defines them, social determinants of health include in their scope various factors, some of them being the social position, the features of social circumstances, and resources with access determined by the social position (Lalonde, 1974; Epp, 1986; Raphael et al., 2004).

\section{Diabetes}

Diabetes is a group of metabolic diseases characterized by hyperglycemia resulting from a defect in production or operation of insulin, which is secreted by the beta cells of the pancreas. Chronic hyperglycemia is connected with damage to, disruption of operation and failure of various body organs, especially eyes, kidneys, heart and blood vessels. Depending on the reason and course of the disease, we can distinguish type 1 and type 2 diabetes, diabetes of pregnant women, and others. However, the most often encountered form of this disease is type 2 diabetes - known as diabetes mellitus.

In 2013, the number of diabetics throughout the world was estimated at 382 million. Among them, about 10 percent of patients suffered from type 1 diabetes, an auto-immunological form of the disease which usually develops in childhood. However, the remaining 90 percent are coping with type 2 diabetes, which can be caused by a whole range of factors (IDF Atlas, 2013). Those causes may be either non-modifiable (and hence beyond the patient's control), like: age, sex, ethnic group or modifiable (and hence can be influenced by pro- or anti-health behaviours), like: incorrect diet, excessive weight/obesity, or insufficient physical activity.

Importantly, modifiable risk factors are closely connected with the occurrence of health inequalities. This is because, throughout the world, the exposure to occurrence of diabetes is not distributed uniformly. There are significant inequalities both in access to healthcare (especially with respect to access to healthcare services dedicated to diabetics and persons from the increased risk group), as well as health inequalities (among others, incorrect diet, too low physical activity) that increase the risk of developing diabetes and translates to possible health-related effects), which can be seen especially well in case of persons with type 2 diabetes. At the same time, we should emphasise that, as a rule, both the risk factors (the modifiable as well as the nonmodifiable ones) and the reasons for inequalities (low socio- economic status, poverty, unemployment, lack of education) will keep accumulating.

Below we analyse both non-modifiable and modifiable factors of type 2 diabetes occurrence and their correlation with inequalities in health and inequalities in access to healthcare.

\subsection{Non-modifiable factors (NHS, 2014):}

\subsubsection{Ethnical factors}

Type 2 diabetes is up to six times more common in South Asia and up to three times more common among the inhabitants of Africa and the Caribbean than among the white race. 
The occurrence of type 2 diabetes is also more common among the people of Chinese origins and other groups of population classified as non-Caucasian ones. Moreover, among those persons, diabetes is diagnosed decidedly more often also among the younger persons. Unfortunately, it is not only the risk of diabetes occurrence that is greater in those parts of the world, but also the risk of diabetes-related death is three to six times higher. In addition, those groups are also especially prone to complications of diabetes within the cardio-vascular system and kidneys.

With respect to health inequalities, a significant role will be played here by their significant differentiation among the individual countries. Other important factors will also include stratification of the society, organization of the healthcare system and the degree of effective utilization of that system's resources.

\subsubsection{Age}

The prevalence of diabetes grows speedily with age: one in twenty persons aged 65 (or more) is suffering from diabetes, and this number grows to one in five persons at the age of 85 years (or more). This can result from the fact that diagnosis of diabetes might be delayed among the elderly, since the symptoms connected with the disease may be mistakenly attributed to the process of physiological aging of the body. In case of a non-modifiable factor like age, there might also be a risk of inequalities in access to healthcare, since elderly people might feel (or really be) discriminated compared to younger persons. This is because the elderly will require interdisciplinary care of the whole system - from guaranteeing and fulfilling their health needs in the area of repair medicine up to caring and nursing actions.

An extremely important issue will also be providing the elderly with the appropriate education, which will allow the patient to become co-responsible for his/her health, to actively influence its shaping, and to fully participate in the therapeutic process.

\subsubsection{Sex}

Type 2 diabetes occurs more often among men than among women. However, despite the above, among the women who have already developed diabetes, there is a greater risk of death than among the male diabetics. Most probably, the reasons for those differences can be seen in the health inequalities. The lower risk of diabetes occurrence among women is connected with their nutritional choices and the observance of nutritional recommendations. What is more, women exhibit the tendency to play the role of a carer when another family member is suffering from diabetes. In turn, the more frequent occurrence of death among diabetic women is most probably connected with the series of hormonal changes that take place in a woman's body in the period around the menopause.

\subsection{Modifiable factors:}

\subsubsection{Socio-economic factors:}

The new approach to civilization diseases (among which type 2 diabetes is also classified) - linking them directly to social exclusion (whereby it may operate both as a cause and as an effect of that phenomenon) has contributed to carrying out numerous scientific studies examining the relationship between the occurrence of civilization diseases and the affluence status of an individual. It has turned out that there is a strict dependence between the individual's income and the risk of heart attack (the dependence is conversely proportional- the higher the income, the lower the risk of heart attack) (Erikkson et al., 2000), as well of heart diseases (Rattue, 2011). An analogous dependence also holds with respect to type 2 diabetes (Dziemidok et al., 2011). The dependence follows, among others, from the fact that less affluent persons have 
limited access to (capability of purchasing) the necessary medicines or observing the appropriate diet, which is especially crucial for type 2 diabetes.

\subsubsection{Incorrect diet}

The difficulty in determining the risk connected with an incorrect diet consists in the problem with defining such an incorrect diet. This is because, as we should keep in mind, the recommendations and assumptions of the diet are tailored to the individual profile of a single person or a group of persons. However, an undeniable fact is that one of the determinants of healthy nutrition is a diet rich in vegetables and fruit, which considerably reduces the risk of cardiovascular diseases, stomach cancer and colon cancer (Bazzano et al., 2003; Riboli, Norat, 2003). Moreover, as many as $16 \mathrm{~m}(1.0 \%)$ DALYs (the number of potential life years lost) and 1.7 $\mathrm{m}(2.8 \%)$ deaths all over the world may be attributed to low consumption of vegetables and fruit (WHO, 2009; WHO 2003). There is also convincing scientific evidence for the fact that consumption of large amounts of high-calorie foods (e.g. highly processed ones), rich in saturated fats and simple sugars, facilitates development of a series of civilization diseases (WHO, 2003), including especially: type 2 diabetes (Meyer, 2001), obesity and cardiovascular diseases.

The capability of observing nutritional recommendations among both the diabetics and persons endangered by the occurrence type 2 diabetes will yet again depend on health inequalities, through factors like socio-economic status (financial resources for buying the appropriate products) or education (the appropriate nutritional education).

\subsubsection{Sufficient physical activity}

A sedentary lifestyle connected with the consumption-oriented model of functioning has become yet another of the leading death risk factors. At present, it is the fourth one from the top in the classification of death factors, which means it causes about $3.2 \mathrm{~m}$ deaths each year (WHO, 2009). Regular physical activity is one of the cheapest and best forms of prevention against numerous diseases, since 150 minutes of moderate exercise weekly helps reduce the risk of ischaemic heart disease by about $30 \%$, of type 2 diabetes by about $27 \%$, and of breast and colon cancers by $21-25 \%$ (WHO, 2010). Similarly as in the above cases, also insufficient physical activity will be correlated with the occurrence of health inequalities (among others, through economic status or education level).

\section{Role of education, health promotion and disease prevention from the viewpoint of diabetes and health inequalities}

Based on the above considerations, we should stress that while in case of nonmodifiable factors (ethnic group, sex, age) the actions that can be undertaken are limited and connected with increasing the operating effectiveness of the healthcare system, in case of modifiable factors (physical activity, diet, socio-economic factors), a special role will be played by the individual and his/her pro- or anti-health behaviours. In turn, those behaviours will be correlated with the occurrence (or absence) of health inequalities.

Differentiation of the social positions leads to differentiation of the health status across the social structure. This dependence results in the phenomena of social inequalities in the health area. Health promotion has been created in order to improve the health status and to decrease social inequalities among the population by building individual or collective resources for health and healthy lifestyle, and assuring their egalitarian distribution. Taking into consideration the tasks of health promotion, we can with full justification assume that implementation of that process creates chances of decreasing social inequalities with regard to health protection. At the same time, health promotion actions directed at socially excluded persons (or persons threatened with 
such exclusion) should take into account the situation of those persons (both health-oriented, and social and economic one).

Similarly to health promotion, the persons affected by (threatened with) social exclusion should be the target of prevention programmes. This is because, as shown in the above text, the occurrence of health inequalities itself is a significant risk factor for the occurrence of type 2 diabetes, and in consequence - the group of socially excluded persons (or persons threatened with such exclusion) constitutes a group with increased risk of type 2 diabetes occurrence.

Those actions are especially important and essential from the viewpoint of the expenditures connected with diabetes. As shown by the statistics, the costs connected with diabetes are higher than the costs connected with all types of cancers taken together. The direct costs of healthcare alone amount already to almost 109 bn. per year in Europe, and will probably increase in future (IDF, 2013). It seems that the only effective method for limiting this huge expenditure is to implement advanced actions in the area of education, promotion of health and prevention of disease throughout the world, but with special focus on the excluded persons, which are particularly threatened with the occurrence of health inequalities and inequalities in access to healthcare.

\section{Conclusion}

The problem of health inequalities gains special importance in the context of diabetes. This is because with this disease the occurrence of health inequalities can be both a cause and an effect.

Persons who are socially excluded, and hence threatened with health inequalities, will at the same time be a group with special risk of type 2 diabetes occurrence. This is because of the assumption that this group of persons may be less educated, and hence less aware of the correct pro-health choices. Moreover, this group will also be to a higher extent threatened with poverty - and hence the economic capabilities of this group will also be limited (substitution of higher quality and more expensive product with lower quality and lower price ones).

At the same time, the occurrence of health inequalities may also be not a cause but rather an effect of developing type 2 diabetes. This is because the disease can limit the possibilities for the diabetic to undertake a money-earning job, significantly interfere with his/her budget (the necessity of observing the appropriate diet, having the tests made, visiting a doctor), as well as affect his/he everyday functioning, and - most importantly - significantly lower the quality of life.

Hence the postulated approach is to give special consideration to persons from the groups threatened with the occurrence of health inequalities in actions concerning education, promotion of health and prevention of diabetes (especially of type 2 diabetes). This will bring benefits not only to the individual persons, but also to the entire societies.

\section{References}

Anderson P., Leppert J., (2001) Men of low socio-economic and educational level possesses pronounced deficient knowledge about risks factors related to coronary heart disease, Journal of Cardiovascular Risk 8: 371-377.

Bazzano LA, Serdula MK, Liu S, (2003) Dietary intake of fruits and vegetables and risk of cardiovascular disease, Current Atherosclerosis Reports, pp. 492-499.

Droomers M., Schrijvers C.T.M., Mackenbach J.P., (2000) Why do lower educated people continue smoking? Explanation from the longitudinal GLOBE study, „Health Psychology”; 21, 3: 263-272.

Dziemidok P., Makara-Studzińska M., Jarosz M.J., (2011) Diabetes and depression: a combination of civilization and life-style diseases is more than simple problem adding - literature review, Annals of Agricultural and Environmental Medicine, 18, pp. 318-322. 
Epp J., (1986) Achieving health for all: a framework, for health promotion, Health and Welfare Canada.

Eriksson J. G., Forsén T., Tuomilehto J., Osmond C., Barker D. J. P., (2000) Early Growth, Adult Income, and Risk of Stroke, American Heart Association Journal, 31, pp. 869-874.

Graham H., (2006) Social determinants and public bealth policy in the UK, in: Killoran A., Swann C., Kelly M.P. (red.), Public health evidence. Teaching health inequalities, Oxford University Press, 63.

IDF (2013) Diabetes Atlas, 6th edition.

Judge K., Platt S., Costongs C., Jurczak K., (2006), Health inequalities: A challenge for Europe, An independent expert report commissioned by the UK presidency of EU.

Kaczmarek T., Marcinkowski J.T., Zysnarska M., Maksymiuk T., Majewicz A.,(2007) Nierówności społeczne w dostepie do zdrowia, Probl. Hig Epidemiol., 88(3), s. 259-266.

Kaplan G.A., Keil J.E., (1993) Socioeconomic factors and cardiovascular disease: a review of the literature. AHA Medical/Scientific Statement, Special Report, „Circulation”; 88; 4, 1: 1973-1988.

King H, Aubert RE, Herman WH. (1999) Global burden of diabetes, 1995-2025: prevalence, numerical estimates, and projections. Diabetes Care; 21: 1414-31.

Lalonde M., (1974) A new perspective on the health of Canadians: a working document, Health and Welfare Canada.

Lynch J.W., Kaplan G.A., Salonen J.T., (1997) Why do poor people behave poorly? Variation in adult health behavior and psychosocial characteristics by stages of socioeconomic lifecourse, „Social Science and Medicine”; 44: 809_ 819.

Meyer KA, Dietary fat and incidence of type 2 diabetes in older Iowa women, Diabetes Care, 2001, pp. 1528-1535.

Pell J.P., Pell A.C.H., Norrie J., Ford I., Cobbe S.M., (2000) Effect of socioeconomic deprivation on waiting time for cardiac surgery: retrospective cohort study, „British Medical Journal”; 320: 15.

Raphael D., Bryant T., Curry-Stevens A., (2004) Toronto charter outlines future bealth policy direction for Canada and elsewhere, „Health Promotion International”; 19: 269-273.

Rattue P., (2011) Lower Income Individuals Have 50\% Higher Risk Of Heart Disease, Medical News Today.

Riboli E., Norat T., (2003) Epidemiologic evidence of the protective effect of fruit and vegetables on cancer risk, American Journal of Clinical Nutrition, 78(Suppl.):pp. 559-569.

Selby JV, Ray GT, Zhang D, et al. (1997) Excess costs of medical care for patients with diabetes in a managed care population. Diabetes Care; 9: 1396-402.

Sowa A., (2007), Społeczne uwarunkowania stanu zdrowia ludności, „Zdrowie Publiczne i Zarządzanie. Zeszyty Naukowe Ochrony Zdrowia", t. V, nr 1-2.

Wamala S.P., Mittleman M.A., Horsten M., Schenck-Gustafsson K., Orth-Gomer K., (2000) Job stress and the occupational gradient in coronary heart disease risk in women. The Stockholm Female Coronary Risk Study, „Social Science and Medicine”; 51: 481-489.

Whitehead M., (1990), The concepts and principles of equity and health, World Health Organization, Kopenhaga.

Wilkinson R., Marmot M., (1998) Social determinants of health, World Health Organization. Regional Office for Europe, Copenhagen.

Włodarczyk W.C., (2006), Polityka zdrowotna Unii Europejskiej: nierówności w zdrowiu, „Zdrowie Publiczne i Zarządzanie. Zeszyty Naukowe Ochrony Zdrowia”, t. IV, nr 2. http://www.nhs.uk/Conditions/Diabetes-type2/Pages/Causes.aspx

World Health Organization, (2003) Diet, nutrition and the prevention of chronic diseases: report of a joint WHO/FAO expert consultation, Geneva.

World Health Organization, (2009) Global health risks: mortality and burden of disease attributable to selected major risks, Geneva.

World Health Organization, (2010) Global recommendations on physical activity for health, Geneva. 
